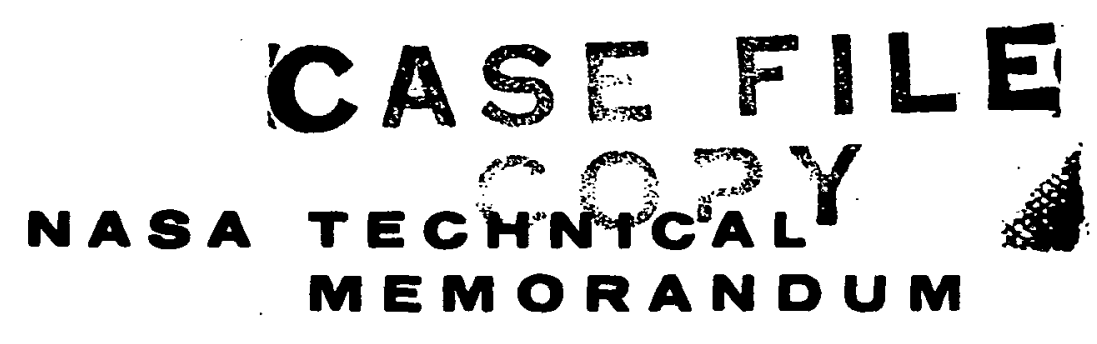

N $73 \quad 32615$

NASA TM $X-71420$

:

\title{
STUDIES OF DISHED ACCELERATOR GRIDS FOR 30-CM ION THRUSTERS
}

by Vincent $\mathrm{K}$. Rawlin

Lewis Research Center

Cleveland, Ohio 44135

TECHNICAL PAPER proposed for presentation at Tenth Electric Propulsion Conference sponsored by the American Institute of Aeronautics and Astronautics Lake Tahoe, Nevada, October 31 - November 2, 1973 


\author{
by Vincent $\mathrm{K}$. Rawlin \\ National Aeronautics and Space Administration \\ Lewis Research Center \\ Cleveland, Ohio
}

\section{Abstract}

Eighteen geometrically different sets of dished accelerator grids were tested on five $30-\mathrm{cm}$ thrusters. The geametric variation of the grids included the grid-to-grid spacing, the screen and accelerator hole diameters and thicknesses, the screen and accelerator open area fractions, ratio of dish depth to dish diameter, compensation, and aperture shape. In general, the data taken over a range of beam currents for each grid set included the minimum total accelerating voltage required to extract a given beam current and the minimum accelerator grid voltage required to prevent electron backstreaming.

\section{Introduction}

Recent studies of solar electric propulsion systems show a need for thruster arrays using 30cm mercury bombardment ion thrusters $(1,2)$. Overall thruster efficiencies over 70 percent are desired at. a maximum input power of approximately 2730 watts and a specific impulse of 3000 seconds. These requirements imply ion beam currents of about 2.0 amperes at net ion energies near 1100 electronvolts from a highly efficient discharge chamber. Reference 3 has shown that dished accelerator grids can easily extract a 2-ampere ion beam from a $30-\mathrm{cm}$ thruster at net ion energies as low as $700 \mathrm{elec}-$ tron-volts. The major advantage which dished grids possess over flat grids with or without interelectrode supports, is that they can be reliably operated with small grid-to-grid spacings under repeated and long term thermal loading of thruster operation. Eighteen sets of dished grids (Table.I) were tested to investigate the effects of grid geometry changes on ion beam extraction. The grid parameters varied were grid hole diameter, grid thickness, fraction open area, ratio of dish depth to dish diameter, compensation, and aperture shape. In adition, many grid sets were tested with various grid-to-grid spacings and several grid sets were tested on more than one of the five different 30-cm thrusters described in Table II.

The following performance parameters were evaluated at various beam currents: the minimum total voltage required to extract a given beam current, the minimum accelerator grid voltage required to prevent electron backstreaming, and the effects of the ratio of net-to-total accelerating valtage.

\section{Apparatus and Procedure}

\section{Ion Accelerator Systems}

The grid sets listed in Table $I$ and used in this study were fabricated from arc-cast molybdenum as described in reference 3 . The aperture sizes, shapes, and center-to-center spacings were varied as well as the dish depth. The grid-to-grid spacings was initially fixed by insulating spacers of synthetic mica for preliminary tests. For long duration tests the dished grids were mounted on molybdenum rings. The cold grid-to-grid spacings were measured by inserting " $L$ " shaped "feeler" gauges, with known thicknesses, between the grids at many locations over the active area of the grid set. The average value of the spacings was used as the cold grid-to-grid spacing for Table III and it was estimated to be accurate to $0.03 \mathrm{~mm}$. All the data presented were obtained with the grids dished away from the discharge chamber.

\section{Thrusters}

Five different 30-cm diameter thrusters were used to test the dished grids. They are described in Table II and references $4,5,6$, and 7 .

\section{Facility and Power Supplies}

$\mathrm{A} 11$ of the tests were conducted in the $3.0 \mathrm{~m}$ diameter bell jar of the $7.6 \mathrm{~m}$ diameter by $21.4 \mathrm{~m}$ long vacuum tank at the Lewis Research Center $(8)$. The bell jar pressure during thruster operation was $3 \times 10^{-6}$ torr while the main tank pressure was $2 \times 10^{-7}$ torr. Power to the thruster was supplied by d.c. and 60 Hertz a.c. power supplies.

\section{Grid Performance Evaluation}

The minimum total accelerating voltage, $\Delta \mathrm{V}_{\mathrm{M}}$, required to extract a given beam current, $J_{B}$, was determined as described in reference 3 and is described briefly here for reference. All symbols are defined in the Appendix.

The minimum total accelerating voltage (the sum of the anode voltage plus the magnitude of the accelerator grid voltage) was determined by noting a rapid increase in the accelerator impingement current, $J_{A}$, with decreasing total voltage. This increase was caused by the inability of the grids to focus the ions through the accelerator holes. Data were obtained while maintaining constant $J_{B}$, discharge voltage, ratio of net-to-total accelerating voltage, and main propellant flow rate.

For purposes of grid comparison it is desirable to determine the ratio of $J_{B}$ at $\Delta V_{M}$ to the theoretically predicted ion current. This ratio has been called the fraction or percentage of Child's law current in references 9 and 10 and is determined through the use of the space charge flow equation for parallel plates:

$$
J_{c}=\frac{8}{9} \epsilon_{0} \quad \frac{q}{2 m} \frac{A_{S} \Delta V \frac{3}{2}}{l^{2}}
$$

where $J_{c}$ is the calculated space charge limited ion current, $\epsilon$ is the permittivity of free space and $\mathrm{q} / \mathrm{m}$ is the charge to mass ratio for ions which are assumed to be singly charged. $A_{S}$ is the area of the ion source, assumed in references 9 and 10 to be the screen grid open area. $\Delta V_{M}$ is the 
minimum total acceleration voltage determined by the above procedure. The ion accelerating distance, $l$, is usually an estimated value which includes the cold grid-to-grid spacing plus some fraction of the screen and/or accelerator grid thicknesses. The value used for $\ell$, in this report, will be defined at a later time.

The minimum accelerator voltage, $\mathrm{V}_{\mathrm{AM}}$, required to prevent electron backstreaming was measured for each grid set as a function of beam current, net accelerating voltage, and grid-togrid spacing. At accelerator grid voltages slightly less than $V_{A M}$ there was a rapid increase in the indicated $J_{B}$ as electrons from the downstream plasma were able to backstream to the positive potential of the discharge chamber.

\section{Results and Discussion}

Minimum Total Accelerating Voltage

One method of evaluating the performance of ion extraction systems is to compare the current carrying capacity of each different set of grids. This can be accomplished by measuring the values of $\Delta V_{M}$ over a range of $J_{B}$ for each grid geometry. This section will present data showing the effects of grid geometry and operating conditions on the current carrying capacities for the grids of Table $I$.

Effect of Thruster Type. Several sets of grids were tested on more than one of the thrusters listed in Table II. In no instance did the performance of any grid set depend significantly upon the thruster type. For example, grid set $K$ was tested on all five thrusters with about a 3 percent variation in $\Delta \mathrm{V}_{\mathrm{M}}$. It was therefore concluded that comparisons of different grids could be made on any of the five thrusters used in the program.

Effect of Discharge Power. The discharge power was increased by a factor of three while operating grid set $M$ at a $J_{B}$ of 2.0 amperes and a propellant utilization efficiency of 0.9 or more. The value of $\Delta V_{M}$, as in reference 3 , did not change with discharge power. In some tests, to obtain higher values of $J_{B}$, the total propellant flow rate was increased above normal because the discharge power was limited. This resulted in much lower propellant utilization and a more peaked plasma density which caused ion defocusing at higher than normal values of $\Delta V_{M}$. All grid data was obtained at the highest value of propellant utilization obtainable unless stated otherwise. It was therefore concluded that the effective ion accelerating distance was unaffected and that different grids could be compared at different levels of discharge power as long as the propellant utilization efficiency was near the maximum possible value.

Effect of the Ratio of Net-to-Total Accelerating Voltage, $R$. The $\Delta V_{M}$ was measured for several grid sets over a range of $J_{B}$ as the ratio of the net-to-total accelerating voltage, $R$, was varied. No noticeable change occurred in $\Delta V_{M}$ when $R$ was decreased from the maximum value (where electron back-streaming occurred) to about 0.4 . This was similar to the results of reference 3 . At values of $R$ less than 0.4 , the accelerator impingement current increased because of defocused ions, which made it difficult to determine $\Delta V_{M}$. It was therefore concluded that grid sets could be compared at different values of $R$ when $R$ was greater than 0.4. The data of Table III were obtained at values of $R$ between 0.57 and 0.70 .

Effect of Beam Current. Figure $I$ is a $\log -\log$ plot of the values of $\Delta V_{M}$ at various values of $\mathrm{J}_{\mathrm{B}}$ for grid set $\mathrm{D}$ taken from Table III. The different curves are for different grid-to-grid spacings. Estimated ion accelerating distances, which will be defined later, are shown in Fig. 1. Figure 1 is typical, in several respects, to the results with the other grid geometries. For a fixed $l$, the functional relationship of $\Delta V_{M}$ to $J_{B}$ was constant over a large range of $J_{B}$, with the exception of tests 6 and 7 where, as indicated previously, abnormally high values of $\Delta \mathrm{V}_{\mathrm{M}}$ at increased values of $J_{B}$ probably resulted from decreased propellant utilization efficiency. In Fig. $1, J_{B}$ increased at a power of $\Delta V_{M}$ greater than the $3 / 2$ power predicted by Eq. (1), for each of the five estimated ion acceleration distances which were varied from 0.98 to $1.41 \mathrm{~mm}$. This was also found in reference 3 and was true for all of the dished grid sets presented herein.

The exact reasons for the deviations from the functional dependence predicted by Eq. (1) are not known. Several phenomena could explain this behavior. They include the variation of effective accelerating distance with $J_{B}$ (and $\Delta V_{M}$ ), variation of beam profiles with $J_{B}$, doubly charged ions, and ions with initial velocities. Also, the multiaperture grids tested, are significantly different than the planar diodes assumed in the derivation of Eq. (1). These different effects will be discussed briefly.

1. Variation of effective ion accelerating distance with $\mathrm{J}_{\mathrm{B}}$. The grid-to-grid spacing could change with discharge power variations as $J_{B}$ is varied. Such power variations would be expected to vary the absolute temperatures and possibly the thermal profiles of both grids. As indicated earlier however, the effects of discharge power variation were insignificant. The grid-to-grid spacing could change with applied voltage as a result of electrostatic forces. Preliminary tests, in atmosphere, indicate that over the range of total accelerating voltages presented herein, there was no observable change in grid spacing with applied voltage. Attempts to measure changes in grid spacing during operation have been unsuccessful. The effective ion accelerating distance could vary if the upstream or downstream plasma boundaries moved as the thruster operating conditions were changed. This has been indicated by Lathem in reference $l 1$.

2. Variation of beam profile with $J_{B}$. Beam profile changes could lead to ion defocusing at a different radial position on the grid. Since the grid-to-grid spacing is not uniform across the grid during operation, ion defocusing at a different radial location probably would result in a different $l$. Preliminary measurements of beam profiles obtained from a planar probe located $2 \mathrm{~cm}$ downstream of the grids.have indicated that the shape of the beam profile was not a function of $J_{B}$ but was slightly dependent on the total accelerating voltage. 
3. Doubly charged ions. The mercury plasma contains dopbly-charged as well as singly-charged ions $(12,13)$. Reference 13 has shown that the integrated double ion content of the ion beam increases with $J_{B}$. The exact extent of the effect of doubly-charged ions is not known but it would contribute to the increased sensitivity of $J_{B}$ to $\Delta V_{M}$ observed in Fig. 1.

4. Initial ion velocity. The initial velocity acquired by the ions as they approach the accelerating region, in effect, allows a reduction of the total accelerating voltage. But the variations of this velocity with variations in $J_{B}$ are only on the order of a few volts and shouid not significantly affect the values of $\Delta V_{M}(14)$.

5. Multi-aperture grids. Equation (1) was derived for a vacuum diode consisting of two parallel plates separated by a uniform spacing. In reality, the accelerator grid set consists of two perforated plates separated by a non-uniform spacing during operation. The effect of the holes, on the variation of grid performance with $J_{B}$ is not known.

Effect of Grid Geometry. This section will present the effects on $\Delta \mathrm{V}_{M}$ of changes in the geometry of the grid set. The results of some of these changes were strongly interrelated. Attempts will be made to separate the results for clarity.

1. Estimated ion accelerating distance, $l$ From Fig. 1 it can be seen that the performance of the dished grids was a strong function of $l$ and that some estimate of the ion accelerating distance was required to compare the experimental results. Reference 3 used the sum of the screen grid thickness and the cold grid-to-grid spacing minus the change in spacing due to thermal loading as the estimated ion accelerating distance. There, the change in effective spacing was estimated to be $0.26 \mathrm{~mm}$. The results of this program, where the accelerator grid thickness was varied, indicated that. the accelerator rid thickness also was important in the determination of the level of extracted ion current. As will be discussed later, threefourths of the accelerator grid thickness was added to the $l$ of reference 3 . Thus, the $l$ used herein is defined as the sum of the screen grid thickness, the cold grid-to-grid spacing, and three-fourths of the accelerator grid thickness minus $0.26 \mathrm{~mm}$ for grids with a ratio of dish depth to dish diameter of 0.075 . Results with grids with a ratio of dish depth to dish diameter of 0.038 indicated the change in spacing, when operated, to be $0.74 \mathrm{~mm}$ and this value, rather than $0.26 \mathrm{~mm}$, was used for those grids with the shallower dish depth.

It should be noted that the selection of this distance was somewhat arbitrary and was chosen as a convenience for the purpose of comparing the different grid types with each other as well as with Eq. (1).

Values of $\Delta V_{M}$ are plotted in Fig. 2 as a function of $l$ for all of the grid sets of Table III operated at a beam current of 2.0 amperes. Note that most of the data lie in a band in which $\Delta V_{M}$ increases with $l$, but in general, slower than the $4 / 3$ power predicted by Eq. (1).

When the values of $\Delta V_{M}$ for other values of $J_{B}$ were plotted as a function of $l$, the trends were the same as those shown in Fig. 2. For this reason, subsequent discussion of the effects of grid geometry variations on grid performance will be made by comparing values of $\Delta V_{M}$ obtained for operation at $\mathrm{J}_{\mathrm{B}}$ of 2.0 amperes only. For completeness, the data at all beam currents is presented in Table III.

Figure 2 can be used to estimate the cold gridto-grid spacing required for a large range of dished grid geometries operated at a value of $J_{B}$ of 2.0 amperes. All that is needed is a knowledge of the $\Delta V_{M}$ required and the thickmess of the screen and accelerator grid.

2. Effect of accelerator grid thickness, $t A$. Figures $3(\mathrm{a})$ and (b) compare the performance of grid set $D$ with $E$ (screen grid open area fraction, $F_{O S}=0.51$ ) and grid set $M$ with $N\left(F_{O S}=0.67\right)$ where the only difference, in each case was $t$ In both instances, the data followed similar trends when the estimated ion accelerating distance included three-fourths of the accelerator grid thickness. When the fraction of $t_{A}$ was omitted from the estimated $l$, as in reference 3 , the values of $\Delta V_{M}$ were greater for the grids with the larger $t_{A}$. This probably occurred because the maximum beamlet diameter in the accelerator hole increased when. $t_{A}$ was increased $(15)$.

3. Effect of screen grid thickness, $t_{s}$. Figure $3($ a) compares the performance of grid sets $D$ and $F$, which were-identical except that $t_{S}$ for grid set $F$ was twice that of $D$. When the larger value of $t_{S}$ was entirely accounted for in $l$, the performance difference was negligible. Comparison of tests 8 and 10 of Table III shows that even though the cold spacings were 0.99 and $0.66 \mathrm{~mm}$ for grid $D$ and F, respectively, the estimated values of $l$ were 1.12 and 1.17 and that the values of $\Delta V_{M}$ over a range of $J_{B}$ were nearly identical.

4. Effects of screen and accelerator grid hole diameters, $\mathrm{ds}_{2} \mathrm{~d}_{\mathrm{A}}$. Figure 4 compares the performance of several grid sets in which only the grid hole diameters were varied. Figure $4(a)$ shows the variation of grid performance with hole diameter for grid sets $B, C$, and $D$ where $F_{O S}$ and $F_{O A}$ were 0.51 . There are only single data points for grid sets $B$ and $C$ because the discharge chamber performance with those grids was relatively poor. For grid set $D\left(d_{S}\right.$ and $d_{A}=1.91 \mathrm{~mm}$ ), Fig. 4(a) shows that there was an increasing sensitivity of $\Delta \mathrm{V}_{M}$ to $l$ as $l$ increased. Also the grids with smaller holes had larger values of $\Delta V_{M}$ than grid set D. It is possible that the non-linear effect for grid set $D$ and the increased values of $\Delta V_{M}$ for grid sets $B$ and $C$ are due to grid open area variations. As suggested in reference 7, to explain the sensitivity of the discharge chamber performance to $l$ for grids with $F_{O S}$ of 0.51 , the effective screen grid hole diameter (plasma surface available for ion extraction) may have been greater than the physical $d_{S}$. It also may have increased with decreasing $l^{S}$ and increasing $d_{S}$.

Figures 4 (b) and (c) also show the effect of grid hole diameter on $\Delta V_{M}$, but for grids with $F_{O S}$ of 0.67 and $F_{O A}$ of 0.67 and 0.43 , respectively. They are both linear with $\&$ and show little or no sensitivity of $\Delta V_{M}$ to $d_{S}$. The probable explanation is that the effective screen grid hole diameter had reached a maximum value for high physical open area grids and was insensitive to 
variations in $d_{S}$ or $\ell$. The same explanation was offered in reference 7 when there were negligible variations in the discharge chamber performance for grids with $F_{O S}$ of 0.67 . Comparison of Fig. 4(b) to 4(c) shows that the slope of Fig. 4(b) (grids with equal hole diameters) was steeper than Fig. 4(c) $\left(d_{A}=0.8 d_{S}\right)$. This effect cannot be explained at this time.

\section{Effect of screen and accelerator grid} open area fraction, FOS, FOA. Figure 5 compares the performance of several grid sets each having equal values of $F_{O S}$ and $F_{O A}$ which ranged from 0.43 to 0.77 . With the exception of grid set $A$ $\left(F_{\mathrm{OS}}=0.43\right)$, the performance of the grids was insensitive to variations in $F_{O S}$. The probable explanation, as presented earlier, is that the effective $F_{O S}$ was larger than the physical $F_{O S}$ and near the maximum of unity for most grids, and therefore insensitive to changes in the physical $F_{0 S}$. The higher value of $\Delta V_{M}$ for grid set $A$ can be attributed to the possibility that the effective $F_{O S}$ was closer in value to the physical $\mathrm{F}_{\mathrm{OS}}$, as discussed earlier.

7. Effect of hole pattern compensation. Figure 6 compares the performance of several grid sets with different amounts of grid hold pattern compensation $(16)$. Compensation (expressed as a percent strain) adjusts the grid hole center-tocenter spacing in a manner which reduces the thrust loss due to beam divergence. For grids with two different geometries, the values of $\Delta V_{M}$ were unaffected by grid hole compensation up to 0.66 percent for grids with $F_{O A}$ of 0.51 and 0.35 percent for grids with $F_{O A}$ of 0.43 .

8. Effect of ratio of dish depth to dish diameter, $h / D$. Reference 3 predicted twice the change in spacing due to thermal loading for dished grids with half the h/D. Comparison of tests 32 and 35 show that nearly the same performance was obtained, for grid sets $R$ and $S$, even though the cold grid spacing differed by more than a factor of two. By assuming that grids with the same performance have the same effective $l$, the change in spacing due to thermal loading was estimated to be $0.74 \mathrm{~mm}$. When this value was used in $h$ for all of the tests of grid set $S$, the performance was equivalent to that of grid set $R$ over a wide range of $l$ as shown in Fig. 7.

Ratio of Experimental $\mathrm{J}_{\mathrm{B}}$ to Calculated $\mathrm{J}_{\mathrm{C}}$.

The space charge limited current, $J_{C}$, was calculated, from Eq. (1), for all of the tests of Table III. The value of $A_{S}$ used was taken to be $6.6 \times 10^{4} \mathrm{sq} . \mathrm{mm}$, the total area of the perforated region of the screen grid without concern for the physical blockage of the webs between the holes. This assumption was made because it was shown earlier that the performance of all but one of the grid sets was insensitive to the physical open area fraction. The $l$ used in the calculation was as defined in the section entitled "Estimated ion accelerating distance." The charge to mass ratio for singly charged ions was used, Using the experimental values of $\Delta V_{M}$, values of $J_{C}$ were obtained. The ratios of the corresponding experimental $J_{B}$ to the calculated value of $J_{C}$ are listed in Table III. Table III shows that in most cases the ratio increased with $J_{B}$ for a fixed $l$.
Figure 8 shows that in general, the ratio of $J_{B}$ to $J_{C}$ increased with $l$ when the grids of Table I were operated at a $J_{B}$ of 2.0 ampere. This effect possibly can be explained by the grid aperture effect which was disçussed in reference 9. Theoretically the ratio of $J_{B}$ to $J_{C}$ should increase with the ratio of $l$ to $d_{S}$ and with $R$. Since the values of $\Delta V_{M}$ were not sensitive to most variations in $d_{S}$ or variations of $R$ when $R$ was greater than 0.4 , the ratio of $J_{B}$ to $J_{C}$ were plotted as a function of $l$ only.

\section{Minimum Accelerator Grid Voltage}

To maximize the accelerator grid lifetime, it is desirable to minimize the accelerator grid voltage in order to reduce the sputtering erosion of incident ions. Reference 16 has also shown that to minimize the thrust loss due to beam divergence it is desirable to maximize the ratio of net-tototal accelerating voltage, $R$. The maximum value of $R$ is limited to that value which prevents electron backstreaming, therefore those parameters which affect $R$ were studied.

Effect of Beam Current, $J_{B}$. Figure 9 shows the variation of the minimum accelerator grid voltage, $\mathrm{V}_{\mathrm{AM}}$, with $\mathrm{J}_{B}$ for most of the grids of Table $\mathrm{I}$. For a given grid set $V_{A M}$ increased gradually with $J_{B}$, increasing only about 80 volts for the most sensitive grid set, as $J_{B}$ was increased from 1.0 to 2.0 amperes.

Effect of Estimated Ion Accelerating Distance, l. Values of $V_{A M}$ were obtained for several grid sets tested over a range of $\ell . V_{A M}$ was not a strong function of $l$ but did decrease slightly as $\ell$ was increased.

Effect of Net Ion Accelerating Voltage, $V_{T}$. Figure 10 presents the variation of $V_{A M}$ with $V_{I}$ for three values of $J_{B}$ for test 20 using grid set $M$. In all cases, $B_{A M}$ increased about 20 volts for every 100 volt increase in $V_{T}$. Therefore, if a use of electric propulsion requires an increasing $V_{I}$, an increase in $V_{A}$ may also be required to avoid electron backstreaming.

Effect of Accelerator Grid Thickness, $t_{A}$ Figure 11 shows the variation of $V_{A M}$ with $\mathrm{J}_{\mathrm{B}}$ for two pairs of grid sets in which only $t_{A}$ was varied. When $t_{A}$ was doubled for grid set $E$, $V_{A M}$ decreased approximately 100 volts at a $J_{B}$ of $2.0 \mathrm{amp}$. The $t_{A}$ for grid set $M$ was increased by 50 percent for grid set $N$ which resulted in a decrease of $V_{A M}$ of about 50 volts. In both cases the increase of $t_{A}$ provided more of a shield of the positive potentials from the neutralizing electrons in the ion beam.

Effect of Accelerator Grid Hole Diameter, $a_{A}$. To separate the effect of $d_{A}$ from the effects of $J_{B}$ and $t_{A}$ variations, values of $v_{A M}$ obtained at $J_{B}$ of 2.0 amperes for only those grid sets with $t_{A}$ equal to 0.38 , were plotted in Fig. 12 as a function of $d_{A}$. As $d_{A}$ was increased from 1.02 to $2.41 \mathrm{~mm} V_{A M}$ also increased from about 140 to 450 volts. The accelerator grid hole diameter had the strongest effect on $V_{A M}$ of any parameter studied and was the chief factor in the determination of the maximm value of the ratio of the netto-total accelerating voltage. 


\section{Grid Iifetime}

Table I lists the total test time in hours that each grid set was operated. The total accumalated test time for the sixteen grid sets used in. this study was 4584 hours. Grid sets $D$ and $H$ each had more than 1550 hours with most of the time occurring at $\mathrm{J}_{\mathrm{B}}$ of 2.0 to 2.5 amperes. Grid performance has been extremely repeatable during extended tests and from test-to-test.

None of the grids tested show wear on the accelerator grid due to neutralizer ions. This resulted from repositioning the neutralizer away from the accelerator grid as suggested by Bechtel in reference 17 and the accelerator grid voltage was 500 volts or less. Typical values of impingement current were 0.2 to 0.3 percent of the beam current. For the grid sets with 1550 accumulated hours the pattern of charge-exchange erosion was visible on the downstream side of the accelerator and was approximately measured to be $0.01 \mathrm{Im}$ deep at the most.

\section{Conclusions}

The minimum total accelerating voltage was measured for eighteen different grid geometries operated over a range of beam currents and grid spacings. The minimum total accelerating voltage was found to be insensitive to thruster type, discharge power variations, and the ratio of the netto-total accelerating voltage when $R$ was greater than 0.4. When compared at a constant value of beam current, the minimum total accelerating voltages, for the dished grids tested in this program having an open area fraction of 0.51 or greater and a screen hole diameter of 1.91 or greater, were primarily a function of only the estimated ion accelerating distance. The ion accelerating distance was estimated to be the sum of the screen grid thickness, the cold grid-to-grid spacing, and three-fourths of the accelerator grid thickness minus the change in the grid-to-grid spacing due to the thermal loading of thruster operation. This insensitivity of the minimum total accelerating voltage to grid geometry changes, other than the estimated ion accelerating distance, led to the conclusion that the effective screen grid open area fraction was constant and nearly unity and therefore unaffected by screen grid hole diameter changes.

Values of space-charge limited ion current were calculated using the experimental values of the minimum total accelerating voltage and the estimated ion accelerating distances. The ratios of experimental beam current to the calculated space charge limited ion current were found to increase with estimated ion accelerating distance at a fixed beam current.

The minimum accelerator grid voltage, required to prevent electron backstreaming to the discharge chamber, increased slightly with increasing ion beam current, decreasing estimated ion accelerating distance, increasing net accelerating voltage, and decreasing accelerator grid thickness. The minimum accelerator grid voltage was found to be a strong function of the accelerator grid hole diameter.

Two sets of dished grids, used in this program, have each accumulated more than 1550 hours of repeatable thruster operation. None of the grids tested had wear from neutralizer ions or chargeexchange ions greater than $0.01 \mathrm{~mm}$ in depth.

\section{Appendix}

Symbols

$A_{S}$ - Area of the ion source, $\mathrm{mm}^{2}$.

$\mathrm{d}_{\mathrm{A}}$ - Accelerator grid hole diameter, $\mathrm{mm}$.

$d_{S}$ - Screen grid hole diameter, mo.

$F_{O A}$ - Accelerator grid open area fraction.

$F_{\text {OS }}$ - Screen grid open area fraction.

h/D - Ratio of dish depth to dish diameter.

$\mathrm{J}_{\mathrm{A}}$ - Accelerator grid impingement current, ma.

$J_{B} \quad$ - Ion beam current, amp.

$J_{C}$ - Space charge limited current, amp.

\& - Estimated ion accelerating distance, $\mathrm{mm}$.

$q / m$ - Charge-to-mass ratio for singly-charged mercury ions, $0.4811 \times 10^{6}$ coulomb $/ \mathrm{kg}$.

R - Ratio of net-to-total accelerating voltage.

$t_{A}$ - Accelerator grid thickness, mm.

$t_{S}$ - Screen grid thickness, $\operatorname{mm}$.

$\mathrm{V}_{\mathrm{A}}$ - Accelerator grid voltage, volts.

$V_{I}$ - Net ion accelerating voltage, volts.

$V_{A M}$ - Minimum accelerator grid voltage, volts.

$\Delta V_{M}$ - Minimum total accelerating voltage.

$\epsilon_{0}$ - Permittivity of free space, $8.85 \times 10^{-12}$ coulomb ${ }^{2} / \mathrm{nt} \cdot \mathrm{m}$.

\section{References}

1. Gardner, J. A., "Solar Electric Propulsion System Integration Technology (SEPSIT). Vol III: Supporting Analysis," TM 33-583, Vol. III, NASA CR-130703, Nov. 1972, Jet Propulsion Lab., Pasadena, Calif.

2. Anon., "Study of a Common Solar-Electric-Propulsion Upper Stage for High-Energy Unmanned Missions. Vol. 2: Technical," Rep. TRW-165526007-RO-00-Vol. 2, NASA CR-114350, July 1971, TRW Systems Group, Redondo Beach, Calif.

3. Rawlin, V. K., Banks, B. A., and Byers, D. C., "Dished Accelerator Grids on a $30-\mathrm{cm}$ Ion Thruster," Journal of Spacecraft and Rockets, Vol. 10, No. 1, Jan. 1973, pp. 29-35.

4. Bechtel, R. T., "Performance and Control of a 30-cm-Diam, Low-Impulse Kaufman Thruster," Journal of Spacecraft and Rockets, Vol. 7, No. 1, Jan. 1970, pp. 21-25. 
5. King, H. J, and Poeschel, R. L., "Low Specific Impulse Ion Engine," NASA CR-72677, Feb. 1970, Hughes Research Labs., Malibu, Calif.

6. Anon., "Low Voltage $30-\mathrm{cm}$ Ion Thruster," NASA CR-120919, Feb. 1972, Hughes Research Labs., Malibu, Calif.

7. Rawlin, V. K., "Performance of $30-\mathrm{cm}$ Ion Thrusters with Dished Accelerator Grids," paper to be presented at the AIAA loth Electric Propulsion Conference, Oct. 31-Nov. 2, 1973.

8. Finke, R. C., Holmes, A. D., and Keller, T. A., "Space Environment Facility for Electric Propulsion Systems Research," TN D-2774, 1965, NASA, Cleveland, Ohio.

9. Kerslake, W. R., "Accelerator Grid Tests on an Electric-Bombardment Ion Rocket," TN D-1168, 1962, NASA, Cleveland, Ohio.

10. Kerslake, W. R., and Pawlik, E. V., "Additional Studies of Screen and Accelerator Grids for Electric-Bombardment Ion Thrusters," TN D-14l], 1963, NASA, Cleveland, Ohio

11. Lathem, W. C., "Analytic Performance of TwoGrid Accelerator Designs for Kaufman Thrusters," TN D-6275, 1971, NASA, Cleveland, Ohio.
12. Pawlik, E. V., Goldstein, R., Fitzgerald, D. J., and Adams, R. W., "Ion Thruster Performance Calibration," Paper 72-475, Apr. 1972, AIAA, New York, N.Y.

13. Vahrenkamp, R., "Measurement of the Double Ion Content of the 30-cm Mercury Bombardment Thrusters," AIAA paper to be presented at the 10th Electric Propulsion Conf., Oct. 31-Nov. 2, 1973.

14. Howes, W. I., "Effect of Initial Velocity on one-Dimensional, Ripolar, Space-Charge Currents," Journal of Applied Physics, Vol. 36, No. 6, June, 1965, pp. 2039-2045.

15. Lathem, W. C., "Ion Accelerator Designs for Kaufman Thrusters," Paper 69-261, Mar. 1969, AIAA, New York, N.Y.

16. Danilowicz, R. L., Rawlin, V. K., Banks, B. A., and Wintucky, E. G., "Measurement of Beam Divergence of $30-\mathrm{cm}$ Diameter Dished Grids," AIAA paper to be presented at the loth Electric Propulsion Conference, oct. 31-Nov. 2, 1973.

17. Bechtel, R. T., "Performance of a Neutralizer for Electron Bombardment Thruster," Paper 72-207, Jan. 1972, AIAA, New York, N.Y.

Table I - Dished Grid Geometry

\begin{tabular}{|c|c|c|c|c|c|c|c|c|c|c|}
\hline \multirow{2}{*}{$\begin{array}{l}\text { Grid } \\
\text { set }\end{array}$} & \multicolumn{2}{|c|}{ Hole diameter, $\mathrm{mm}$} & \multicolumn{2}{|c|}{ Grid thickness, mm } & \multicolumn{2}{|c|}{ Open area fraction } & \multirow{2}{*}{$\begin{array}{c}\text { Compen- } \\
\text { sation, } \\
\epsilon \%\end{array}$} & \multirow{2}{*}{$\begin{array}{c}\text { Aperture } \\
\text { shape }\end{array}$} & \multirow{2}{*}{$\begin{array}{l}\text { Ration of } \\
\text { dish depth } \\
\text { to dish } \\
\text { diameter }\end{array}$} & \multirow{2}{*}{$\begin{array}{c}\text { Total } \\
\text { test } \\
\text { time, } \\
\text { hr }\end{array}$} \\
\hline & Screen & Accelerator & Screen & Accelerator & Screen & Accelerator & & & & \\
\hline A & 1.52 & 1.52 & 0.51 & 0.51 & 0.43 & 0.43 & 0 & Circular & 0.075 & 84 \\
\hline $\begin{array}{l}B \\
C \\
D \\
E \\
F \\
G \\
H \\
J\end{array}$ & $\begin{array}{l}1.02 \\
1.27 \\
1.91 \\
1\end{array}$ & $\begin{array}{l}1.02 \\
1.27 \\
1.91 \\
1\end{array}$ & $\begin{array}{r}0.38 \\
.38 \\
.38 \\
.38 \\
.76 \\
.38 \\
.38 \\
.38\end{array}$ & $\begin{array}{r}0.38 \\
.38 \\
.38 \\
.76 \\
.38 \\
.38 \\
.38 \\
.38\end{array}$ & 0.51 & 0.51 & $\begin{array}{r}0.22 \\
.44 \\
.66\end{array}$ & Circular & 0.075 & $\begin{array}{r}7 \\
52 \\
1552 \\
5 \\
5 \\
6 \\
33 \\
13\end{array}$ \\
\hline $\begin{array}{l}K \\
\mathrm{~L}\end{array}$ & $\begin{array}{l}1.91 \\
2.41\end{array}$ & $\begin{array}{l}1.91 \\
2.41\end{array}$ & $\begin{array}{r}0.38 \\
.38\end{array}$ & $\begin{array}{r}0.38 \\
.38\end{array}$ & $\begin{array}{r}0.67 \\
.67\end{array}$ & $\begin{array}{r}0.67 \\
.67\end{array}$ & $\begin{array}{l}0 \\
0\end{array}$ & $\begin{array}{l}\text { Circular } \\
\text { Circular }\end{array}$ & $\begin{array}{r}0.075 \\
.075\end{array}$ & $\begin{array}{r}1580 \\
205\end{array}$ \\
\hline $\begin{array}{l}M \\
N \\
0 \\
P \\
Q\end{array}$ & $\begin{array}{l}1.91 \\
1.911 \\
1.91 \\
2.16 \\
2.41\end{array}$ & $\begin{array}{l}1.52 \\
1.52 \\
1.52 \\
1.73 \\
1.93\end{array}$ & 0.38 & $\begin{array}{r}0.51 \\
.76 \\
.76 \\
.76 \\
.76\end{array}$ & 0.67 & 0.43 & $\begin{array}{c}0 \\
0 \\
0.35 \\
0 \\
0\end{array}$ & Circular & 0.075 & $\begin{array}{r}332 \\
382 \\
73 \\
10 \\
135\end{array}$ \\
\hline $\begin{array}{l}\mathrm{R} \\
\mathrm{S}\end{array}$ & $\begin{array}{l}2.08 \\
2.08\end{array}$ & $\begin{array}{l}2.08 \\
2.08\end{array}$ & $\begin{array}{r}0.38 \\
.38\end{array}$ & $\begin{array}{r}0.38 \\
.38\end{array}$ & $\begin{array}{r}0.77 \\
. \quad .77\end{array}$ & $\begin{array}{r}0.77 \\
.77\end{array}$ & $\begin{array}{c}0 \\
0.097\end{array}$ & $\begin{array}{l}\text { Hexagonal } \\
\text { Hexagonal }\end{array}$ & $\begin{array}{r}0.075 \\
.038\end{array}$ & $\begin{array}{r}110 \\
23\end{array}$ \\
\hline
\end{tabular}


Table II - $30 \mathrm{~cm}$ Thruster Geometry

\begin{tabular}{|c|c|c|l|}
\hline Thruster & $\begin{array}{c}\text { Basic } \\
\text { thruster } \\
\text { design }\end{array}$ & $\begin{array}{c}\text { Thruster } \\
\text { descrip- } \\
\text { tion }\end{array}$ & \multicolumn{1}{|c|}{$\begin{array}{c}\text { Major differences } \\
\text { from basic design }\end{array}$} \\
\hline A & LeRC & Ref. 4 & None \\
\hline B & HRL300 & Ref. 5 & None \\
\hline C & HRL400 & Ref. 6 & Active magnetic baffle \\
\hline D & HRL300 & Ref. 1 & $\begin{array}{l}\text { Active magnetic baffle, axial } \\
\text { and radial electromagnets }\end{array}$ \\
\hline E & HRL400 & Ref. 1 & $\begin{array}{l}\text { Active magnetic baffle, shorter } \\
\text { cathode pole piece, stronger } \\
\text { magnetic field }\end{array}$ \\
\hline
\end{tabular}

Table ITI - Performance of Grids of Table I

\begin{tabular}{|c|c|c|c|c|c|c|c|c|}
\hline Test & Thruster & $\begin{array}{l}\text { Grid } \\
\text { set }\end{array}$ & $\begin{array}{l}\text { Cold grid } \\
\text { spacing, } \\
\mathrm{mm}\end{array}$ & $\begin{array}{c}\text { Estimated ion } \\
\text { accelerating } \\
\text { distance, } l, \\
\mathrm{~mm}\end{array}$ & $\begin{array}{c}\text { Beam } \\
\text { current, } \\
\mathrm{J}_{\mathrm{B}}, \mathrm{A}\end{array}$ & $\begin{array}{c}\text { Minimum } \\
\text { total } \\
\text { accelerating } \\
\text { voltage, } \\
\Delta \mathrm{V}_{\mathrm{M}}, \mathrm{v}\end{array}$ & $\begin{array}{c}\text { Ratio of } \\
\text { experimental } \\
J_{\mathrm{B}} \text { to cal- } \\
\text { culated } \mathrm{J}_{\mathrm{C}} \text {, } \\
\text { percent }\end{array}$ & $\underset{R}{\operatorname{Maximum}}$ \\
\hline 1 & B & A & 0.76 & 1.40 & $\begin{array}{l}0.7 \\
1.0 \\
1.5 \\
2.0\end{array}$ & $\begin{array}{r}920 \\
1120 \\
1370 \\
1680\end{array}$ & $\begin{array}{l}19.2 \\
20.6 \\
22.7 \\
22.6\end{array}$ & 0.90 \\
\hline 2 & C & B & 0.56 & 0.98 & $\begin{array}{l}1.0 \\
1.5 \\
2.0\end{array}$ & $\begin{array}{r}900 \\
960 \\
1080\end{array}$ & $\begin{array}{l}14.0 \\
19.2 \\
24.3\end{array}$ & 0.90 \\
\hline 3 & B & $\mathrm{C}$ & 0.86 & 1.28 & $\begin{array}{l}1.0 \\
1.5 \\
2.0\end{array}$ & $\begin{array}{l}1300 \\
1530 \\
1690\end{array}$ & $\begin{array}{l}13.8 \\
16.2 \\
18.5\end{array}$ & 0.90 \\
\hline 4 & B & $\mathrm{D}$ & 0.56 & 0.98 & $\begin{array}{l}1.0 \\
1.5 \\
2.0 \\
2.5\end{array}$ & $\begin{array}{r}680 \\
810 \\
940 \\
1040\end{array}$ & $\begin{array}{l}21.3 \\
24.5 \\
26.2 \\
28.2\end{array}$ & 0.75 \\
\hline 5 & B & $\mathrm{D}$ & 0.66 & 1.08 & $\begin{array}{l}0.7 \\
1.0 \\
1.5 \\
2.0 \\
2.5\end{array}$ & $\begin{array}{r}630 \\
720 \\
870 \\
1000 \\
1090\end{array}$ & $\begin{array}{l}23.0 \\
27.0 \\
30.5 \\
32.9 \\
36.1\end{array}$ & 0.75 \\
\hline 6 & B & D & 0.81 & 1.23 & $\begin{array}{l}0.7 \\
1.5 \\
2.0 \\
2.5 \\
2.9\end{array}$ & $\begin{array}{r}740 \\
960 \\
1140 \\
1350 \\
1650\end{array}$ & $\begin{array}{l}20.7 \\
30.2 \\
31.0 \\
30.1 \\
25.8\end{array}$ & 0.76 \\
\hline 7 & B & D & 0.86 & 1.28 & $\begin{array}{l}0.7 \\
1.5 \\
2.0 \\
2.5 \\
3.0\end{array}$ & $\begin{array}{r}740 \\
1000 \\
1140 \\
1260 \\
1420\end{array}$ & $\begin{array}{l}22.4 \\
30.4 \\
33.5 \\
36.0 \\
36.2\end{array}$ & 0.76 \\
\hline 8 & A & D & 0.99 & 1.41 & $\begin{array}{l}1.0 \\
1.5 \\
2.0\end{array}$ & $\begin{array}{l}1030 \\
1210 \\
1380\end{array}$ & $\begin{array}{l}25.5 \\
27.8 \\
30.5\end{array}$ & 0.78 \\
\hline
\end{tabular}


Table III - Performance of Grids of Table I (cont.)

\begin{tabular}{|c|c|c|c|c|c|c|c|c|}
\hline Test & Thruster & $\begin{array}{c}\text { Grid } \\
\text { set }\end{array}$ & $\begin{array}{c}\text { Cold grid } \\
\text { spacing } \\
\mathrm{mm}\end{array}$ & $\begin{array}{c}\text { Estimated ion } \\
\text { accelerating } \\
\text { distance, } l, \\
m m\end{array}$ & $\begin{array}{c}\text { Beam } \\
\text { current, } \\
J_{B}, A\end{array}$ & $\mid \begin{array}{c}\text { Minimum } \\
\text { total } \\
\text { accelerating } \\
\text { voltage, } \\
\Delta \mathrm{v}_{\mathrm{M}}, \mathrm{v}\end{array}$ & $\begin{array}{c}\text { Ratio of } \\
\text { experimental } \\
\mathrm{J}_{\mathrm{B}} \text { to cal- } \\
\text { culated } \mathrm{J}_{\mathrm{C}} \\
\text { percent }\end{array}$ & $\underset{\mathrm{R}}{\text { Maximum }}$ \\
\hline 9 & $E$ & $E$ & 0.66 & 1.36 & $\begin{array}{l}0.5 \\
1.0 \\
2.0\end{array}$ & $\begin{array}{r}790 \\
950 \\
1270\end{array}$ & $\begin{array}{l}16.4 \\
25.9 \\
32.2\end{array}$ & 0.85 \\
\hline 10 & $E$ & $\mathrm{~F}$ & 0.66 & 1.46 & $\begin{array}{l}0.5 \\
1.0 \\
1.5 \\
2.0\end{array}$ & $\begin{array}{r}790 \\
1040 \\
1220 \\
1430\end{array}$ & $\begin{array}{l}13.3 \\
25.9 \\
28.8 \\
31.0\end{array}$ & 0.80 \\
\hline 1.1 & $\mathrm{C}$ & G & 0.51 & 0.93 & 2.0 & 890 & 25.6 & 0.75 \\
\hline 12 & E & $\mathrm{H}$ & 0.81 & 1.23 & $\begin{array}{l}1.0 \\
1.5 \\
2.0\end{array}$ & $\begin{array}{r}880 \\
1090 \\
1220\end{array}$ & $\begin{array}{l}22.8 \\
25.9 \\
28.0\end{array}$ & 0.75 \\
\hline 13 & $\mathrm{C}$ & $J$ & 0.86 & 1.28 & $\begin{array}{l}1.0 \\
1.5 \\
2.0\end{array}$ & $\begin{array}{r}840 \\
1040 \\
1250\end{array}$ & $\begin{array}{l}26.4 \\
28.8 \\
29.2\end{array}$ & 0.78 \\
\hline 14 & B & K & 0.66 & 1.08 & $\begin{array}{l}1.0 \\
1.5 \\
2.0\end{array}$ & $\begin{array}{r}790 \\
900 \\
1010\end{array}$ & $\begin{array}{l}20.7 \\
25.5 \\
28.9\end{array}$ & 0.74 \\
\hline 15 & A & K & 0.73 & 1.15 & $\begin{array}{l}1.0 \\
1.5 \\
2.0\end{array}$ & $\begin{array}{r}900 \\
1010 \\
1130\end{array}$ & $\begin{array}{l}19.2 \\
24.3 \\
27.3\end{array}$ & 0.76 \\
\hline 16 & B & L & 0.58 & 1.00 . & $\begin{array}{l}1.0 \\
1.5 \\
2.0 \\
2.5 \\
3.0\end{array}$ & $\begin{array}{r}610 \\
730 \\
860 \\
960 \\
1120\end{array}$ & $\begin{array}{l}26.0 \\
30.7 \\
31.3 \\
33.1 \\
31.4\end{array}$ & 0.70 \\
\hline 17 & B & I & 0.76 & 1.18 & $\begin{array}{l}1.5 \\
2.0 \\
2.5 \\
3.0\end{array}$ & $\begin{array}{r}940 \\
1130 \\
1260 \\
1380\end{array}$ & $\begin{array}{l}28.7 \\
28.9 \\
30.8 \\
32.3\end{array}$ & 0.7 .1 \\
\hline 18 & B & L & 1.02 & 1.43 & $\begin{array}{l}1.0 \\
1.5 \\
2.0 \\
2.5 \\
3.0 \\
3.5 \\
4.0\end{array}$ & $\begin{array}{l}1020 \\
1250 \\
1470 \\
1660 \\
1820 \\
2400 \\
2830\end{array}$ & $\begin{array}{l}24.8 \\
27.4 \\
28.6 \\
29.8 \\
31.1 \\
24.0 \\
21.4\end{array}$ & 0.78 \\
\hline 19 & $\mathrm{E}$ & M & 0.46 & 0.97 & 1.0 & 790 & 16.7 & 0.82 \\
\hline 20 & $E$ & M & 0.68 & 1.19 & $\begin{array}{l}1.0 \\
1.5 \\
2.0\end{array}$ & $\begin{array}{r}940 \\
1040 \\
1090\end{array}$ & $\begin{array}{l}19.4 \\
24.9 \\
30.9\end{array}$ & 0.84 \\
\hline 21 & $\mathrm{E}$ & M & 0.73 & 1.24 & $\begin{array}{l}0.5 \\
1.0 \\
1.5 \\
2.0 \\
2.5\end{array}$ & $\begin{array}{r}810 \\
940 \\
1080 \\
1120 \\
1240\end{array}$ & $\begin{array}{l}13.2 \\
21.0 \\
25.5 \\
32.2 \\
34.7\end{array}$ & 0.85 \\
\hline 22 & $E$ & M & 0.92 & 1.42 & 2.0 & 1280 & 34.6 & $0.8 ;$ \\
\hline 23 & $\mathrm{E}$ & $\mathrm{N}$ & 0.51 & 1.21 & $\begin{array}{l}1.35 \\
2.0\end{array}$ & $\begin{array}{r}960 \\
1110\end{array}$ & $\begin{array}{l}26.2 \\
31.0\end{array}$ & 0.80 \\
\hline
\end{tabular}


Table III - Performance of Grids of Table L (conc.)

\begin{tabular}{|c|c|c|c|c|c|c|c|c|}
\hline Test & Thruster & $\begin{array}{c}\text { Grid } \\
\text { set }\end{array}$ & $\begin{array}{l}\text { Cold grid } \\
\text { spacing } \\
\text { mm }\end{array}$ & $\begin{array}{c}\text { Estimated ion } \\
\text { accelerating } \\
\text { distance, } l, \\
\mathrm{~mm}\end{array}$ & $\begin{array}{c}\text { Beam } \\
\text { current, } \\
\mathrm{J}_{\mathrm{B}}, \mathrm{A}\end{array}$ & $\begin{array}{c}\text { Minimum } \\
\text { total } \\
\text { accelerating } \\
\text { voltage, } \\
\Delta \mathrm{v}_{\mathrm{M}, \mathrm{v}}\end{array}$ & $\begin{array}{c}\text { Ratio of } \\
\text { experimental } \\
J_{B} \text { to cal- } \\
\text { culated } J_{C} \text {, } \\
\text { percent }\end{array}$ & $\begin{array}{c}\text { Maximum } \\
\mathrm{R}\end{array}$ \\
\hline 24 & $\mathrm{E}$ & N & 0.63 & 1.33 & $\begin{array}{l}1.0 \\
1.5 \\
2.0\end{array}$ & $\begin{array}{r}940 \\
1060 \\
1200\end{array}$ & $\begin{array}{l}24.2 \\
31.6 \\
33.4\end{array}$ & 0.84 \\
\hline 25 & $\mathrm{E}$ & $N$ & 0.97 & $\begin{array}{r}1.66 \\
.\end{array}$ & $\begin{array}{l}0.8 \\
1.0 \\
2.0\end{array}$ & $\begin{array}{l}1060 \\
1160 \\
1460\end{array}$ & $\begin{array}{l}25.1 \\
27.7 \\
38.8\end{array}$ & 0.86 \\
\hline $26 \dot{0}$ & D & 0 & 0.92 & 1.61 & 2.0 & 1350 & 41.0 & 0.89 \\
\hline 27 & $\mathrm{C}$ & P & 1.02 & 1.71 & $\begin{array}{l}1.0 \\
1.5 \\
2.0\end{array}$ & $\begin{array}{l}1130 \\
1270 \\
1360\end{array}$ & $\begin{array}{l}30.2 \\
39.1 \\
45.8\end{array}$ & $0.8 ?$ \\
\hline 28 & B & Q & 0.76 & 1.46 & $\begin{array}{l}1.5 \\
2.0\end{array}$ & $\begin{array}{l}1130 \\
1260\end{array}$ & $\begin{array}{l}30.3 \\
34.4\end{array}$ & 0.80 \\
\hline 29 & A & Q & 0.84 & 1.54 & $\begin{array}{l}1.5 \\
2.0\end{array}$ & $\begin{array}{l}1200 \\
1360\end{array}$ & $\begin{array}{l}29.5 \\
32.6\end{array}$ & 0.82 \\
\hline 30 & $\mathrm{C}$ & $Q$ & 0.94 & 1.64 & $\begin{array}{l}1.0 \\
1.5 \\
2.0\end{array}$ & $\begin{array}{l}1180 \\
1370 \\
1500\end{array}$ & $\begin{array}{l}23.0 \\
27.4 \\
32.2\end{array}$ & 0.83 \\
\hline 31 & $\mathrm{C}$ & Q & 1.25 & 1.94 & $\begin{array}{l}1.0 \\
1.5 \\
2.0\end{array}$ & $\begin{array}{l}1.410 \\
1560 \\
1620\end{array}$ & $\begin{array}{l}28.0 \\
36.2 \\
45.5\end{array}$ & 0.84 \\
\hline 32 & B & $\mathrm{R}$ & 0.43 & 0.85 & $\begin{array}{l}1.5 \\
2.0 \\
2.5 \\
3.0 \\
4.0 \\
5.0\end{array}$ & $\begin{array}{r}790 \\
900 \\
960 \\
1050 \\
1300 \\
1800\end{array}$ & $\begin{array}{l}19.1 \\
20.9 \\
23.4 \\
24.9 \\
24.0 \\
19.3\end{array}$ & 0.64 \\
\hline 33 & $c$ & $\mathrm{R}$ & 1.14 & 1.56 & $\begin{array}{l}1.0 \\
2.0\end{array}$ & $\begin{array}{r}980 \\
1340\end{array}$ & $\begin{array}{l}31.2 \\
39.1\end{array}$ & 0.73 \\
\hline 34 & B & $\mathrm{R}$ & 1.40 & 1.82 & $\begin{array}{l}1.0 \\
1.5 \\
2.0 \\
2.5\end{array}$ & $\begin{array}{l}1020 \\
1240 \\
1480 \\
1620\end{array}$ & $\begin{array}{l}40.0 \\
44.8 \\
45.8 \\
50.0\end{array}$ & 0.74 \\
\hline 35 & C & S & 0.91 & 0.85 & $\begin{array}{l}1.0 \\
1.5 \\
2.0\end{array}$ & $\begin{array}{l}6.30 \\
770 \\
880\end{array}$ & $\begin{array}{l}17.8 \\
19.8 \\
21.7\end{array}$ & 0.73 \\
\hline 36 & $\mathrm{C}$ & S & 1.17 & 1.10 & $\begin{array}{l}1.0 \\
1.5 \\
2.0\end{array}$ & $\begin{array}{r}830 \\
920 \\
1010\end{array}$ & $\begin{array}{l}19.8 \\
25.5 \\
29.5\end{array}$ & 0.73 \\
\hline 37 & $c$ & $S$ & 1.98 & 1.92 & $\begin{array}{l}1.0 \\
1.5 \\
2.0\end{array}$ & $\begin{array}{l}1400 \\
1450 \\
1510\end{array}$ & $\begin{array}{l}27.7 \\
39.3 \\
49.3\end{array}$ & 0.77 \\
\hline
\end{tabular}




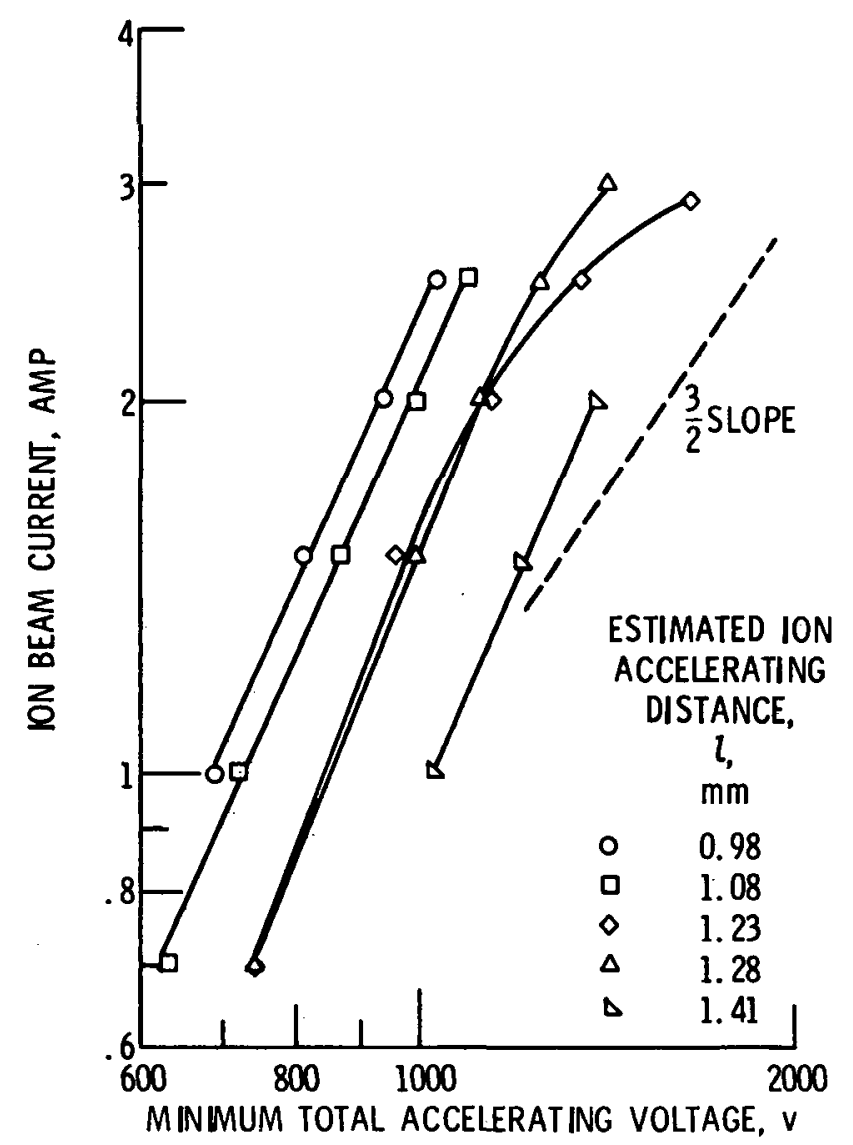

Figure 1. - In beam current as a function of minimum total accelerating voltage for grid set $D$.

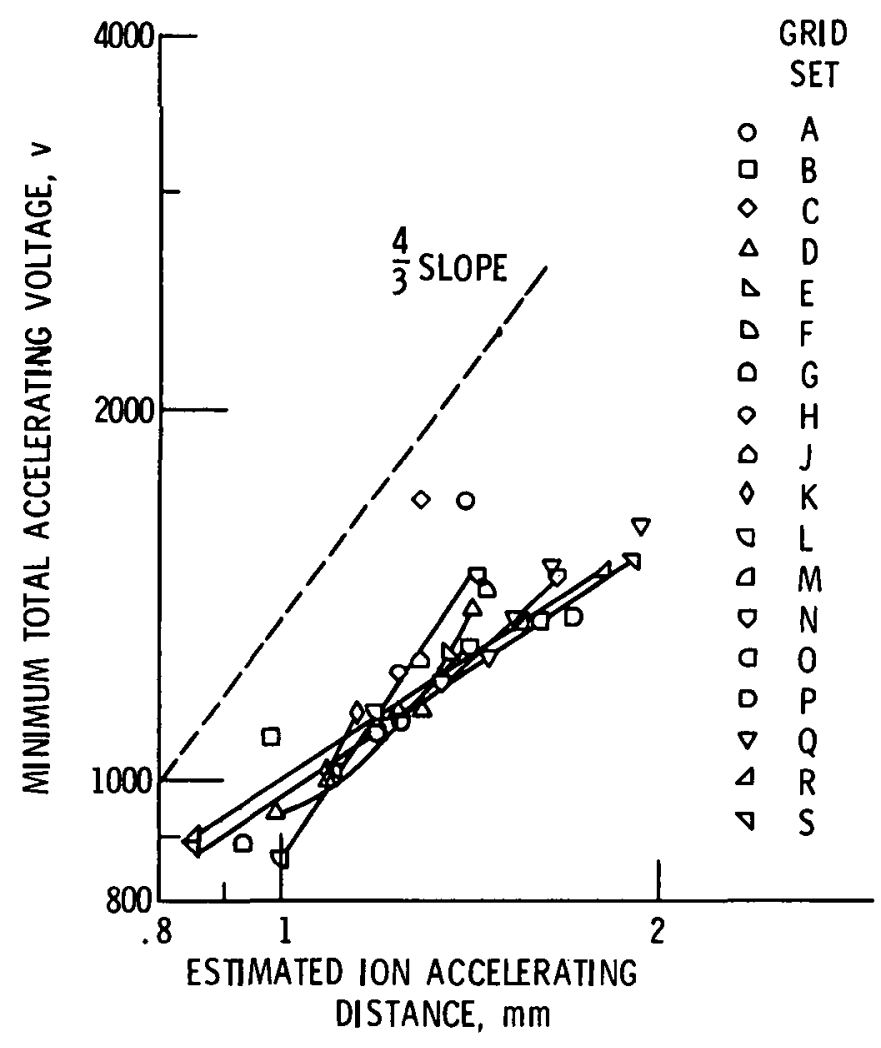

Figure 2. - Minimum total accelerating voltage as a function of estimated ion accelerating distance for grid sets of table III operated at 2.0 amperes beam current. 


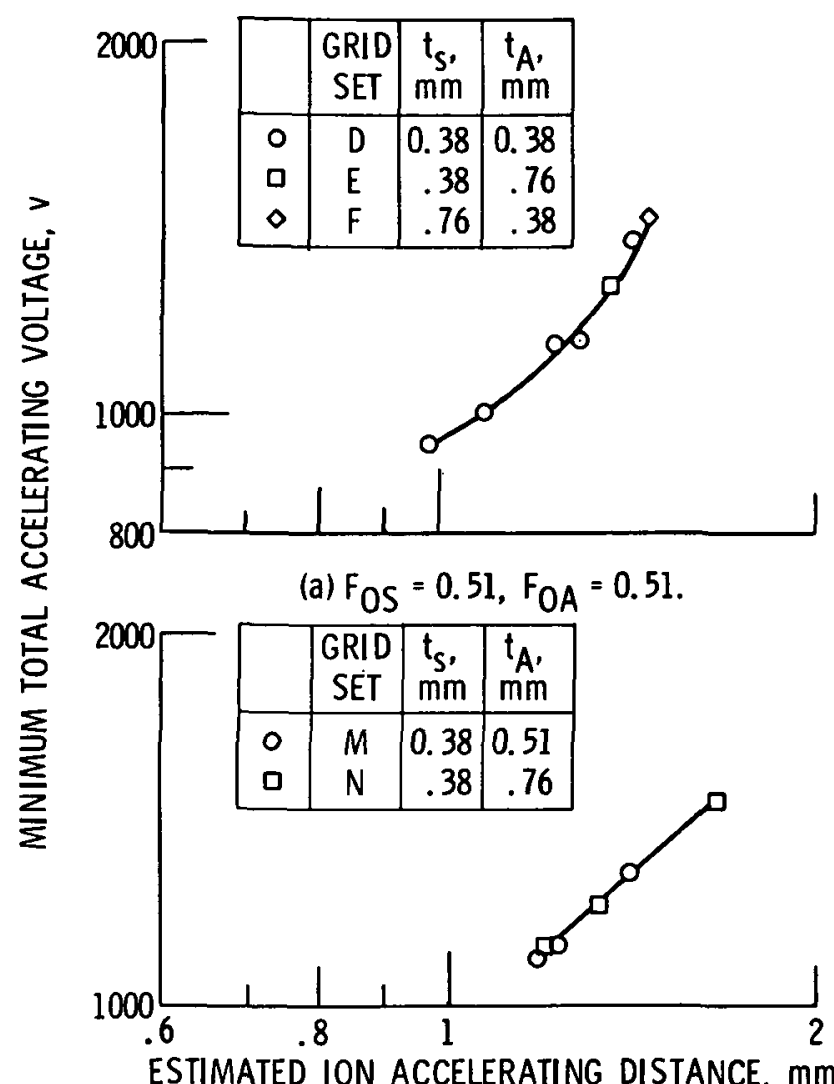

(b) $F_{O S}=0.67, F_{O A}=0.43$.

Figure 3. - Grid performance variation with screen and acceleration grid thickness. 


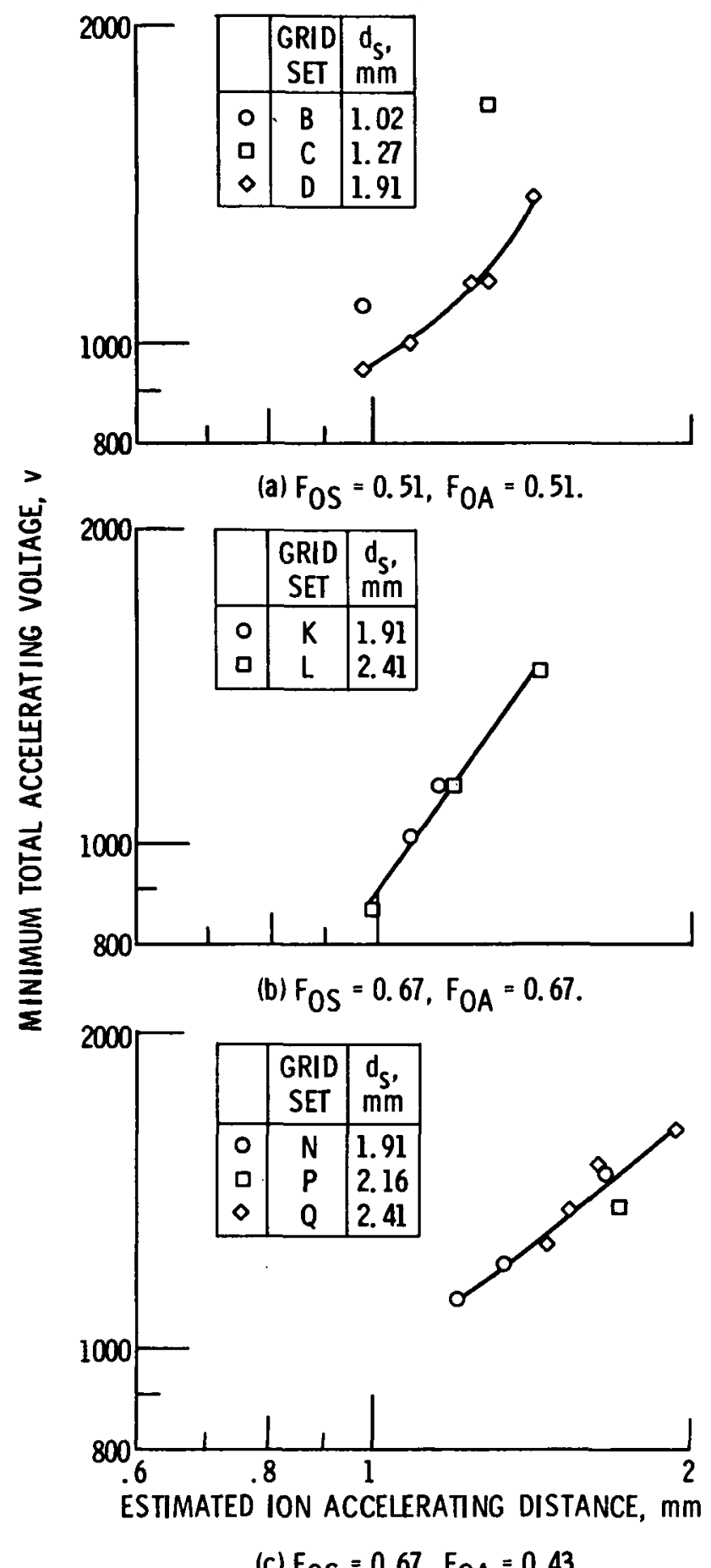

(c) $F_{O S}=0.67, F_{O A}=0.43$.

Figure 4. - Grid performance variation with screen and accelerator grid hole diameters. 


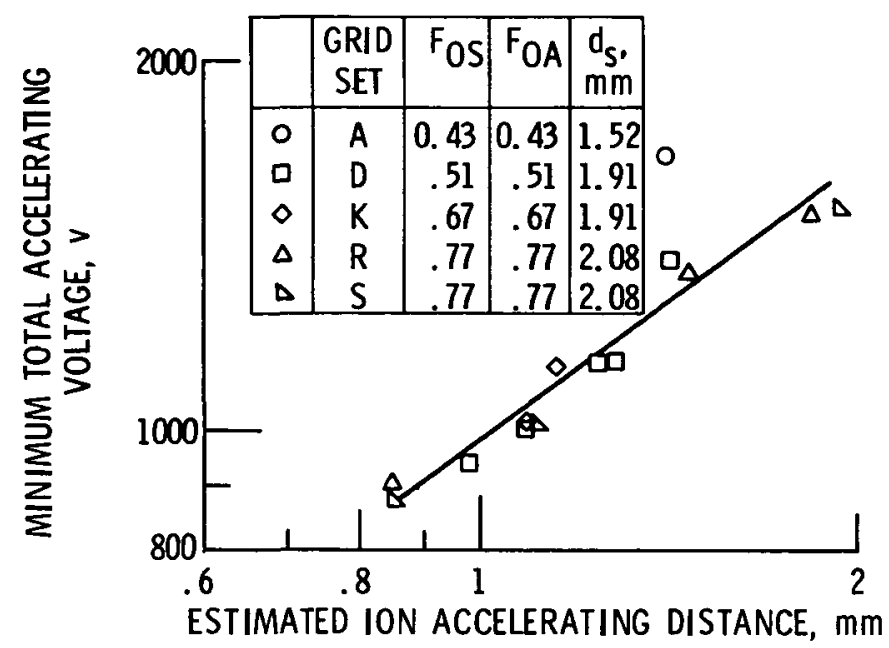

Figure 5. - Grid performance variation with screen and accelerator grid open area fractions.

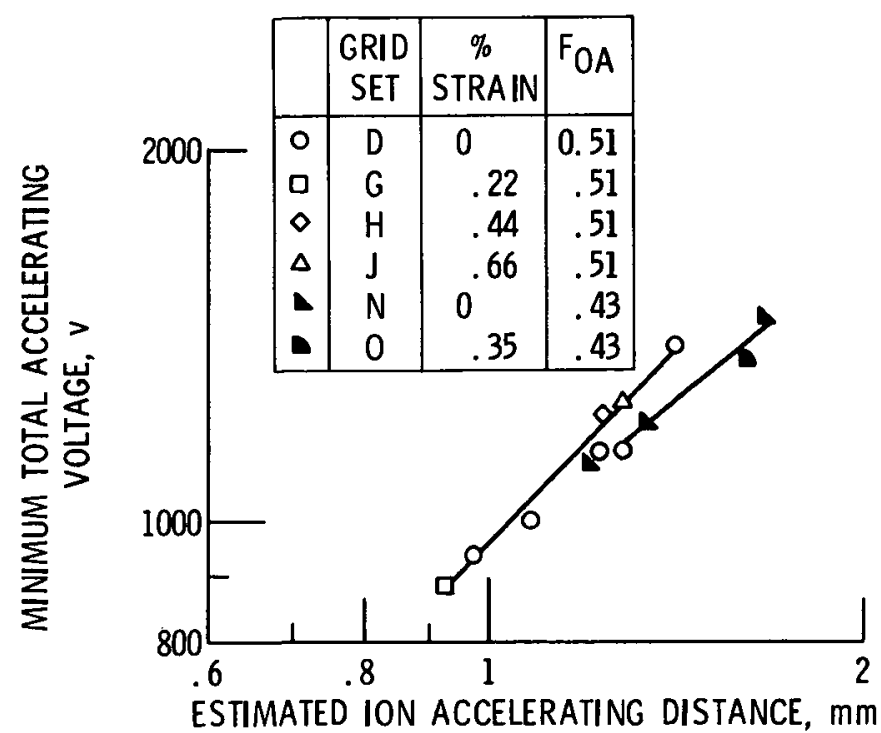

Figure 6. - Grid performance variation with grid hole pattern compensation. 


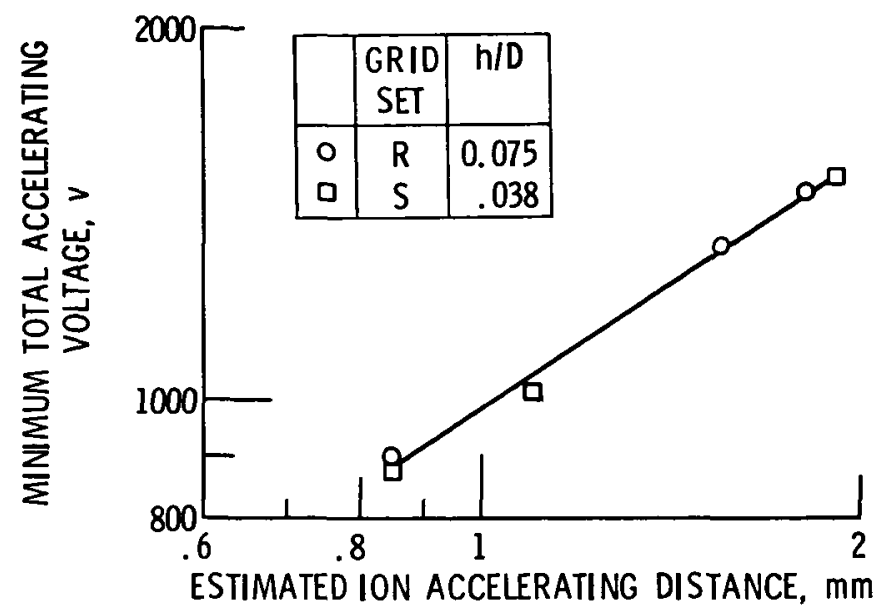

Figure 7. - Grid performance variation with ratio of dish depth to dish diameter.

0
0
0
1
1
1

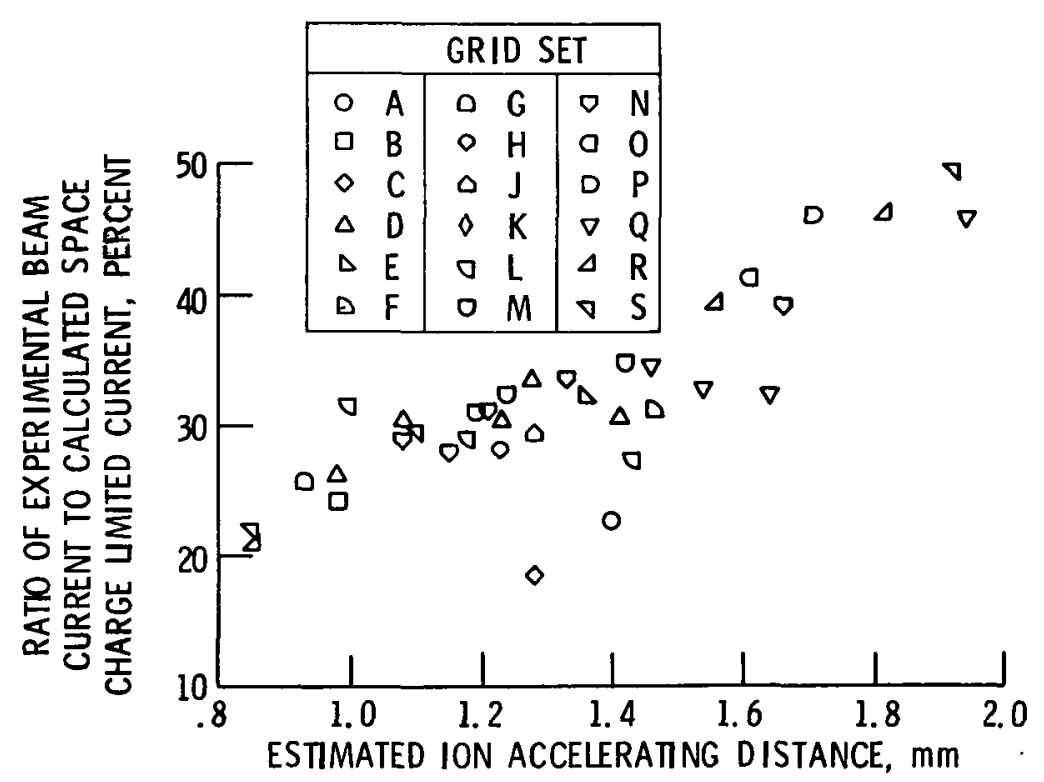

Figure 8. - Ratio of experimental beam current to calculated space charge limited current as a function of estimated ion accelerating distance for an experimental beam current of 2.0 amperes. 


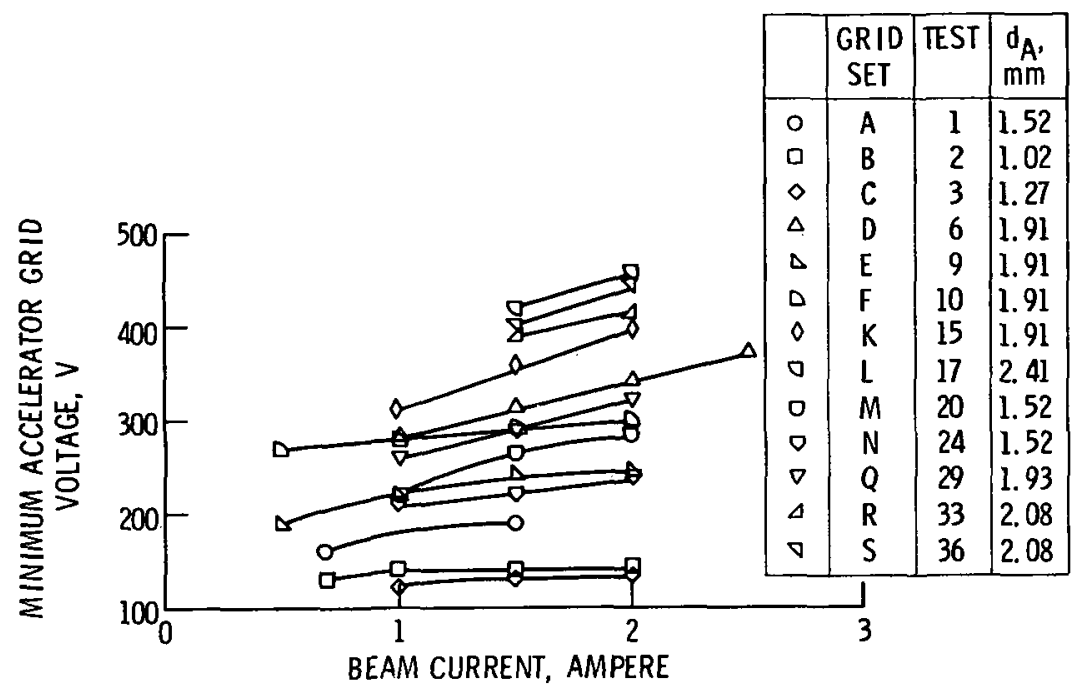

Figure 9. - Minimum accelerator grid voltage as a function of beam current for the grids of Table III $\left(\mathrm{V}_{\mathrm{I}} \approx 1100 \mathrm{v}\right)$.

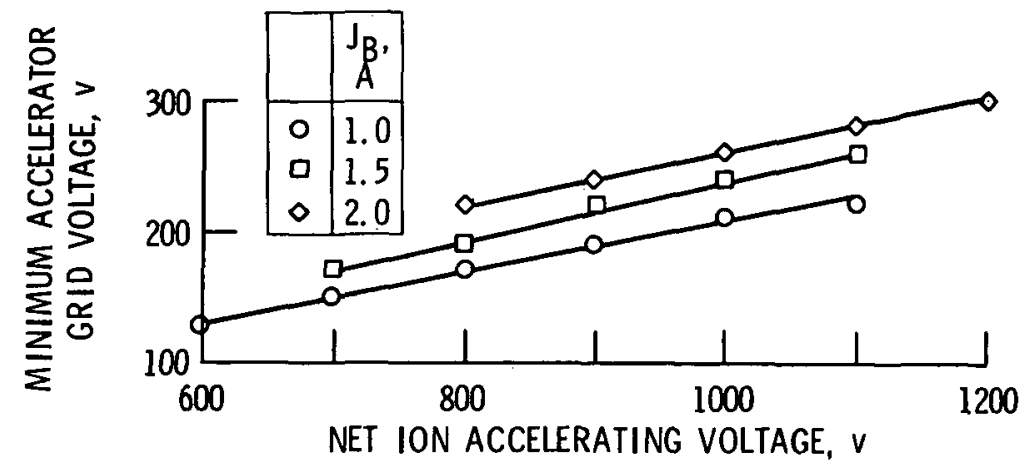

Figure 10. - Minimum accelerator grid voltage as a function of net ion accelerating voltage for grid set $M$, test 20 . 


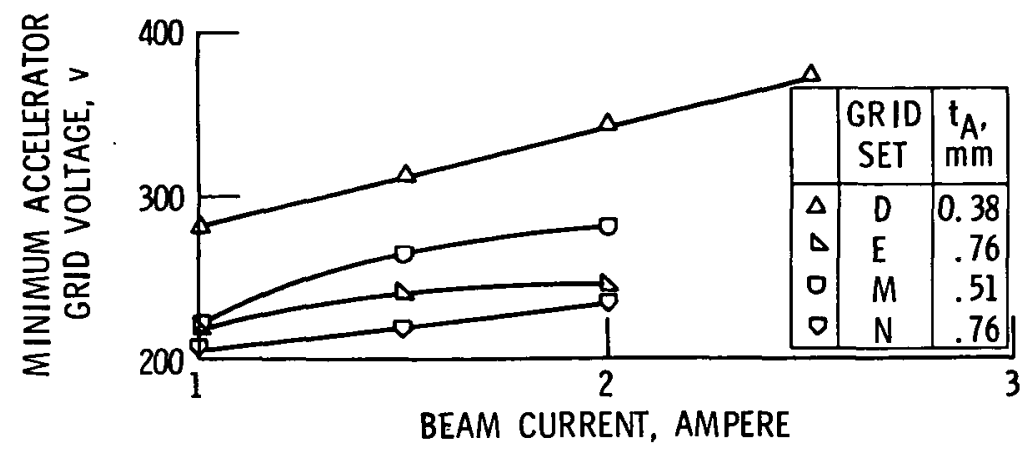

Figure 11. - Variation of the minimum accelerator grid voltage with accelerator grid thickness.

0
0
0
1
$i$
1

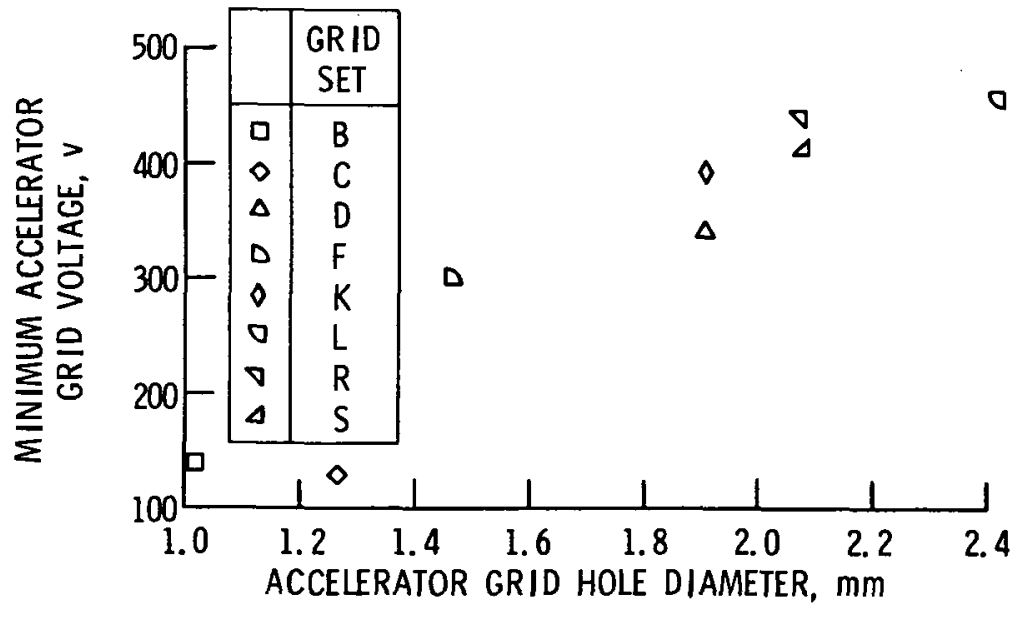

Figure 12. - Minimum accelerator grid voltage as a function of accelerator grid hole diameter for grids with accelerator grid thickness of 0.38 millimeter and beam current of 2.0 amperes. 